\title{
La Intervención Social como forma de Investigación Social: Abuso Sexual Infantil y Terapia Narrativa
}

\author{
Social Intervention as social research: \\ Child sexual abuse and narrative therapy
}

Alexis Bustos Villarroel ${ }^{1}$

\section{Resumen}

El presente artículo pretende abordar y problematizar los métodos clásicos de investigación social. Para tales efectos, se realizará un análisis de caso en la temática de abuso sexual infantil, abordaje que se enmarca desde la terapia narrativa, resaltando la dimensión ético-política de la intervención/investigación social. Para estos efectos, se tomará como referencia un abordaje particular, denominado ceremonia de definición, la cual recopila información sumamente significativa, toda vez que esta emerge desde la vivencia misma de las víctimas de abuso, y como ello, puede sedimentar un elemento recopilación de información, para generar nuevas formas de abordaje en temáticas tan sensibles como lo es el abuso sexual infantil. De esta forma, la novedad que se pretende mostrar en el presente artículo, es el hecho que son las propias víctimas las que asesoran a otras, en la temática que las vincula: el abuso sexual infantil

Palabras Clave: Investigación social, intervención social, terapia narrativa, abuso sexual infantil.

\begin{abstract}
This article aims to address and problematize the classic methods of social research. For this purpose, a case analysis will be carried out on the topic of child sexual abuse, an approach that is framed from narrative therapy, highlighting the ethical-political dimension of social intervention/research. For these purposes, a particular approach will be taken as a reference, called a definition ceremony, which collects extremely significant information, since it emerges from the very experience of the victims of abuse, and as such, it can sediment an element of information gathering, to generate new ways of approaching issues as sensitive as child sexual abuse. In this way, the novelty that is intended to be shown in this article is the fact that it is the victims themselves who advise others, on the theme that links them: child sexual abuse
\end{abstract}

Key words: Social research, social intervention, narrative therapy, child sexual abuse.

\footnotetext{
1. Trabajador Social, Licenciado en Trabajo Social, Postítulo en Psicología Familia y Derecho, Postítulo en Psicología Jurídica al Servicio de la Investigación Forense y Criminal, Formación en Terapia Familiar Sistémica, Formación en Terapia Narrativa, Magíster en Filosofía mención Pensamiento Contemporáneo, Universidad de Valparaíso. Doctor (C) en Psicología Clínica y de la Salud, Universidad de Barcelona, España. Docente de pre y post grado en universidades de la zona centro del país (Universidad de Valparaíso, Universidad Santo Tomás y Universidad Bolivariana), co-fundador de Metáfora: Centro de Terapia del Trauma. Mail: bustosvillarroel@gmail.com - abustovi53@alumnes.ub.edu
} 


\section{Intervención e Investigación Social}

Desde sus inicios, el Trabajo Social ha estado vinculado a la actividad de la intervención social, primeramente, con personas y familias, luego con grupos y posteriormente con comunidades y colectivos. De este modo, podemos entender por intervención social "una acción específica del trabajador social en relación con los sistemas o procesos humanos para producir cambios" (Escartín, 1998, p. 27), siendo una característica de la intervención social la metodología que subyace a la base de ella. En el caso del trabajo social y sus clásicas metodologías. Aquí hallamos el gran punto de encuentro con el proceso de investigación social, en tanto ella "es un conjunto de procesos sistemáticos, críticos y empíricos que se aplican al estudio de un fenómeno o problema" (Hernández, Fernández y Baptista, 2014, p. 4). Por su parte, la intervención busca cambiar o transformar una realidad en particular, entonces la investigación social, buscará la exploración, descripción, correlación o explicación indagación de un fenómeno social cualquiera, pero esa indagación, puede estar direccionada a establecer cambios en "esa" realidad observada. De esta forma, tanto la intervención y la investigación comparten aspectos metodológicos, aunque son distintos entre ellos poseen propósitos comunes.

Existe otro concepto que se entremezcla entre la intervención e investigación social: la generación de conocimiento. En ambas actividades de corte social, se genera un conocimiento en particular. Ya sea en investigación cuantitativa, cualitativa, mixta o multimodal, como también en intervención individualfamiliar, grupal o colectiva, en ambas actividades se generará un espacio de desarrollo de conocimiento, en la investigación ello ocurre de manera deliberada y es lo que se busca, y en intervención ocurrirá conforme avance el proceso metodológico. La generación de conocimiento que emerge de la intervención social, contribuye a depurar los modelos en trabajo social, de esta manera, Carballeda (2004) afirma que existe una íntima relación entre la intervención en lo social y la construcción de conocimiento, señalando que ese conocimiento puede dar diferentes sentidos y redireccionar la intervención social (Carballeda, 2004: 84). Entonces, en el devenir de la intervención social misma, se va desarrollando progresivamente un proceso dialéctico entre la intervención-investigación, dando pie a la generación de un nuevo conocimiento, un conocimiento emergente, que contribuye a reformular el conocimiento anterior. De este modo, el proceso de retroalimentación, es que la intervención puede posicionarse como una forma particular de investigación social. Si asumimos ello y lo llevamos al campo de la intervención terapéutica en materias de abuso sexual infantil, tendremos que los conocimientos que emergen allí, posicionarán nuevas formas comprensivas del tema, ya que, serán las propias víctimas las que generen el conocimiento situado, a través de un diseño narrativo o biográfico de investigación en un contexto de intervención. Lo cual, es sumamente consecuente con lo que se pretende ejemplificar acá, a través de la terapia narrativa y el mapa de ceremonias de definición y testigos externos que, veremos más adelante.

\section{Intervención e Investigación Social}

Existe bastante evidencia de que el abuso sexual infantil -en adelante ASI-, es un problema de salud pública, porque genera efectos a largo plazo en la salud global de las víctimas (Pereda, 2009), por lo tanto, es un problema de salud, que no en todos los países es considerado como tal ${ }^{2}$ y ese es el gran compromiso pendiente en distintas sociedades de América Latina y El Caribe Al mismo respecto, se estima que el 35\% de las mujeres en todo el mundo han sufrido algún tipo de violencia sexual ${ }^{3}$, sumado a ello unos

2. El caso de Chile, por ejemplo, el abuso sexual infantil no forma parte de la política social en relación a la salud pública.

3. Organización Mundial de la Salud, Departamento de Salud Reproductiva e Investigación, Escuela de Higiene y Medicina Tropical de Londres, Consejo Sudafricano de Investigaciones Médicas (2013). Estimaciones mundiales y regionales de la violencia contra la mujer: prevalencia y efectos de la violencia conyugal y de la violencia sexual no conyugal en la salud, p. 2. Para obtener información individual por países, véase The World's Women 2015, Trends and Statistics, capítulo 6, Violence against Women, Departamento de Asuntos Económicos y Sociales de las Naciones Unidas, 2015 y Base de datos mundial sobre la violencia contra las mujeres de ONU Mujeres. 
120 millones de niñas de todo el mundo (1 de cada 10) han sufrido algún tipo de agresión, vejación, obligación u otro tipo de relaciones sexuales forzadas en algún momento de sus vidas. ${ }^{4}$

En lo que concierne a Chile, Según el informe del Ministerio Público, entre enero y septiembre del 2017 ingresaron 16.366 acusaciones, de las cuales el 75,8\% la víctima era menor de 18 años, de esta forma aumenta en 8,1\%, el total de denuncias efectuadas al mismo mes, durante el año 2016.

Respecto de la figura del agresor o agresora, los estudios son determinantes en informar que, la mayoría de las agresiones, obedece a carácter intrafamiliar, o sea, es alguien de la confianza de ese niño, niña o joven, quien los transgrede en el área de la sexualidad. De esta forma, en un estudio interno del Proyecto de Reparación de Maltrato Grave CAVAS Regional Valparaíso, el año $2013^{5}$, se señala que un $86 \%$ de las víctimas durante el periodo consignado corresponde a víctimas de género femenino y los agresores ascienden a un $98 \%$ correspondientes al género masculino, de estos un $28 \%$ corresponde al padre biológico y un $15 \%$ a la pareja de la madre, también, se identifican otras figuras como otros familiares cercanos con un 19\%, vecinos con un $15 \%$, personal del ámbito educativo $1 \%$ y agresoras sexuales de género femenino con un $2 \%$. Y es acá donde la conceptualización del ASI como un problema social, cobra relevancia, ya que, este tipo de transgresión es eminentemente relacional y el daño, se instala en ese mismo ámbito.

A pesar de existir avances teóricos y metodológicos respecto del ASI, los diversos autores que estudian y trabajan con el fenómeno, concuerdan que, es complejo de analizar, dada sus características y los distintos efectos que tiene, tanto de las víctimas directas como en las personas que acompañan a las víctimas, como es el caso de la familia, los adultos significativos y los testigos del abuso. Como se ha descrito ampliamente en la literatura especializada en el tema (Finkelhor, 1997, 1999; Perone y Nanini, 1996; Schore, 2012; Pereda, 2009; Van der Kolk, 2005, 2015; Stupiggia, 2010, entre otros), los cambios y consecuencias suelen interferir desde el nivel neurobiológico, expresándose en una constelación sintomatológica observable (pérdida de confianza, culpa, temores generalizados, hipersensibilización a los estímulos, hipoactivación, etc.) vivida en un contexto sociorelacional (interaccional, afectación de los distintos sistemas de pertenencia socioafectivos; como el colegio, iglesia, grupo de pares, etc.).

En general los dominios comprometidos (Van der Kolk, 2005), son: apego, biología, regulación afectiva, disociación, patrones conductuales, cognición y autoconcepto.

Autores como Echeburúa y Guerricaechevarría (2000), Pereda (2009) y Stupiggia (2010), hacen mención a que, los efectos que suelen observarse con mayor frecuencia, son los psicológicos y en sobre ellos establecen una clasificación que tiende a ordenar y evidenciar cuáles son las áreas de expresión sintomatológica que se reitera en la mayoría de los casos. De esta forma, identifican las siguientes áreas afectadas: afectaciones emocionales, cognitivos, relacionales, sociales, conductuales y sexuales. Sumado a ello, hay que mencionar los efectos del ASI en lo que concerniente al funcionamiento cerebral, de forma tal, que:

Entonces, las principales manifestaciones fenomenológicas observables de las consecuencias del abuso sexual infantil se traducirán en una serie de "síntomas" o "indicadores" tales como: aumento crónico del estrés basalhipersensibilidad ", menor control cognitivo de los afectos en situaciones menos predecibles y cambiantes, dificultades en el procesamiento integrado de la información social, estados afectivos negativos persistentes, experiencias repetidas de terror y miedo pueden ser impresas en los circuitos del cerebro como estados de la mente

(Bustos, A y Vidal, C. 2014).

4. UNICEF (2014). Ocultos a plena luz: Un análisis estadístico de la violencia contra los niños, p. 167.

5. Análisis cuantitativo descriptivo, que contempló medidas de tendencia central y gráficas. Cohorte temporal septiembre

2012 a mayo 2013. Cuyos aspectos metodológicos fueron: $\mathrm{N}=51, \mathrm{~m}=47,43, \mathrm{e}=5 \%$ y $\mathrm{C}=99$

6. También pueden presentarse efectos de hiposensibilidad, reactividad o aplanamiento emocional y conductual. 
En este sentido autores como Van der Kolk (2005, 2015), y Van der Hart (2005), señalan que, los efectos del ASI a la larga, conllevan un serio problema de desregulación neurofisiológica en distintos niveles: desregulación afectiva y fisiológica, desregulación de la atención y la conducta, desregulación del yo y relacional, síntomas disociativos, relacionales y de auto-atribuciones. Estos autores señalan, que el daño incide también la dimensión social, a la cual denomina disminución funcional y abarca los siguientes sistemas de pertenencia: escuela, familia, grupo de semejantes, sistema legal, salud y profesional (Van der Kolk, 2015, p. 411 y ss.) es importante mencionar que, los aportes de Van der Kolk y Van der Hart, provienen de años de estudios desde las neurociencias, por lo cual, es concordante los efectos y sintomatología que se mencionaban con anterioridad, desde la esfera psicológica y social.

\section{Problema social y daño a la confianza}

En el apartado anterior, se pudo visualizar de resumida forma, los distintos efectos que tienen las experiencias de ASI en las niñas, niños o jóvenes. De igual forma, ese daño no solo afecta a la víctima, sino también existe un daño a la familia y las personas cercanas a la víctima, y en ello, es sumamente probable que se instale una nueva crisis -adhiriéndose a la constelación sintomatológica y a las serias desregulaciones- esta crisis se instala desde la población infantojuvenil hacia el mundo adulto y esa crisis; es la crisis de confianza.

Cuando es un adulto el que genera el daño, trauma, abuso en una etapa sensible como es la niñez o la adolescencia, la desconfianza emerge como forma de afrontamiento y protección frente al mundo adulto, frente a los hombres en general y en el habitual de las interacciones que sostiene ese niño, niña o joven.

La confianza es vitalmente impactada, porque, precisamente es la confianza la que fue traicionada, tergiversada, desvirtuada y finalmente violada -en el amplio sentido de la palabra-. Entonces, con la inminente crisis de confianza, ese niño, niña o joven que fue víctima de ASI "debe" seguir el curso de su vida, en la escuela, con su familia, con sus amigos y donde quiera que genere o haya generado lazos de confianza y relación.

Es habitual también, que la crisis de confianza se traslade a otros ámbitos de interacción de los niños, niñas y jóvenes víctimas de ASI. De esta manera, la desconfianza, esa forma de relación en la cual, el miedo se generaliza y amplifica hacia los otros, la incapacidad de sentir o mantener sensaciones de seguridad estables en el tiempo y en general, sensaciones, pensamientos o creencias del potencial daño que pueden llegar a efectuar otros. Todo ello, es consecuente con el modelo traumatogénico de Finkelhor y Browne (1988), donde la traición de la figura de cuidado o figura cercana, quien debería ejercer roles de cuidado, lo que en definitiva ha hecho, es transgredirlo. Sumado a ello, la estigmatización experimentada, la cual se basa en todas esas significaciones de carácter negativo que profiere el agresor y también, la sociedad, contribuyen a que las víctimas se vayan aislando y sintiendo únicas en su experiencia de abuso, sintiéndose diferentes al resto del grupo de pares.

Surge aquí, una de las mayores dificultades del trabajo con niños, niñas y jóvenes que han vivido y sobrevivido a las experiencias de ASI. La posibilidad de generar espacios de confianza y contextos potencialmente seguros. Es aquí donde confluimos con los planteamientos que efectúa Murillo (2012), respecto de la confianza lúcida, la confianza como una propuesta ética en la relación con los otros. Entonces la confianza lúcida "es la confianza que se compromete con ella misma, porque sabe que no puede constituirse como un lugar de certezas absolutas, ni como un valor que se gana de una vez y para siempre" (Murillo, 2012, p. 50). El punto de partida de esta confianza, es que, no parte de las certezas objetivas, de decir y poner en práctica artilugios de la confianza ciega o de la pura desconfianza. La confianza lúcida es una ética que transita por el camino del medio. Otro aspecto fundamental es que la 
confianza lúcida "no descansa en ninguna ideología ni política ni religiosa ni científica" (Murillo, 2012, p. 50). Es una ética que surge en el mundo, en el interactuar con otros, no por el hecho de estar revestida de colores políticos o aspectos de la religión o de la ciencia, estos aspectos no tienen cabida en algo que surge con-otros, no impuesta desde unos para otros, y, finalmente la confianza lúcida es la que tiene claridad de los límites, de las relaciones, de la corporalidad de uno mismo, en relación con otros. Poniendo especial énfasis en los aspectos de los límites, en tanto, son ellos los que permiten reconocerse a uno mismo a partir de otros (Murillo, 2012). Y el tema de los límites es un aspecto fundamental cuando se trabaja en ASI, ya que han sido los límites, los que han sido transgredidos por el ejercicio de poder de un adulto -generalmente-.

Entonces, el espacio terapéutico es una gran posibilidad de generar espacios de confianza lúcida y espacios potencialmente seguros, en primera instancia, bridada por un adulto bientratante -figura del o la terapeuta-, y en segundo momento, de mayor importancia aún, la figura de otros niños, niñas o jóvenes que pueden colaborar en los procesos de otros niños que también han sido víctima de ASI.

\section{Terapia Narrativa}

Respecto de la Terapia Narrativa, podemos señalar que fue propuesta por los Trabajadores Sociales Michael White (Australia), y David Epston (Nueva Zelanda)? Ambos, en 1980 formalizaron sus ideas en un libro llamado "Medios Narrativos para fines terapéuticos", en conjunto, se encontraban trabajando con ideas poco ortodoxas en el campo de la terapia familiar. De esta forma, emerge uno de los planteamientos centrales en la práctica narrativa: la externalización de los problemas, que luego se transformaría en una ética de trabajo. El problema ya no es la persona (teorías analíticas), o la relación (teorías sistémicas), sino, el problema es el problema. "De esta forma, al separar el problema de la persona, se genera un espacio simbólico de profundización, control, manejo y disminución de la situación problemática" (Bustos, 2014, p. 67).

Por ideas "poco ortodoxas" se hace referencia, en primera instancia a las disciplinas que representan David Epston y Michael White, quienes no pertenecen al campo de la psicología o psiquiatría, quienes históricamente han desarrollado modelos, técnicas y teorías en el campo de la terapia familiar y psicoterapia. Si bien, tanto en Australia como en Nueva Zelanda, existe apertura a quienes quieran perfeccionarse como terapeutas familiares, las propuestas en dicha área, se caracterizaban -hasta ese entonces- por profesionales de la psicología y la psiquiatría.

En segunda instancia, las ideas propuestas por David Epston se relacionaban con los ritos de pasaje, propuestos por Van Gennep, trabajados por el antropólogo Víctor Turner, la comprensión de los fenómenos de Clifford Geertz (Antropólogo). Por su parte Michael White estuvo interesado en la epistemología de Gregory Bateson ${ }^{10} \mathrm{y}$ en los planteamientos generales sobre el poder-conocimiento del Filósofo ${ }^{11}$ Michel Foucault, los planteamientos de Jerome Brunner, respecto de su teoría en general, Jacques Derrida, Filósofo, de quien retoma los planteamientos acerca de la deconstrucción ${ }^{12}$ y la crítica textual.

7. Si bien, David Epston posee nacionalidad neozelandesa, es originario de Canadá.

8. Aunque el título original del libro propuesto por los autores se llamaba: Medios Narrativos para fines Literarios. La editorial decide arbitrariamente cambiar la palabra literarios por terapéuticos.

9.También ocurre en E.E.U.U., Canadá, España, Inglaterra, entre otros países, donde los trabajadores sociales cumplen roles terapéuticos.

10. Antropólogo.

11. Los autores mencionados aquí, no son la complitud basal de la terapia narrativa, existen otros autores que, por motivos de forma y espacio, no serán nombrados aquí.

12. M. White plantea diferencias fundamentales entre lo que él entiende por deconstrucción y lo que plantea J. Derrida al respecto. Para mayor información puede consultar el libro Márgenes de la Filosofía de Jacques Derrida (1998), y más precisamente el texto Carta a un amigo japonés, contenido en el libro Psyché (2017), del mismo autor. Para profundizar aspecto de la terapia narrativa en relación con la deconstrucción, véase el libro (en español) Guías para una terapia familiar sistémica (2004) en inglés: Seleted Papers (1989). 
Como se aprecia, los autores basales en los que se apoyan Epston y White, se relacionan con campos de acción distintos de la psicología y la psiquiatría, disciplinas dominantes hasta el momento, en terapia familiar y psicoterapia. En línea con lo anterior, estos planteamientos parecieran desafiar en cierto punto a los planteamientos hegemónicos de la psicología dominante de la época; rebeldía que se muestra como "poco ortodoxa" también por el hecho de incorporar aspectos socioculturales, contextuales y políticos al espacio terapéutico y sobre todo, por distanciarse del positivismo (el problema es la persona) de las teoría de sistemas (el problema es la relación) y quedarse en un pensamiento crítico, contemporáneo y despatologizador (el problema es el problema).

La práctica narrativa ${ }^{13}$ expone que el término "terapia" es un concepto inadecuado para describir el trabajo que se realiza desde esta práctica. En el entendimiento que, el concepto de terapia aduce al tratamiento de enfermedades, desórdenes, defecto, etc., en la práctica narrativa, no se entienden los problemas personales, que en definitiva son el reflejo y producto de problemas sociales más amplios, en términos de enfermedades, defectos o déficits y no se cree en nada que pueda relacionarse con una "curación" (White, 1993). Existe una visión despatologizadora, descentrada del diagnóstico. Lo que no quiere decir, que se invalide o se desconozca lo anteriormente mencionado, sino que el diagnóstico o la patología, es parte de una historia más amplia y en ningún caso, la patología o el diagnóstico va a definir a la persona en su totalidad.

Respecto de la posición de las personas como agentes en sus propias vidas, Michael White y David Epston realizan una comparación acerca de la representación del modo lógico científico y del modo narrativo sobre cómo se entiende al ser humano, desde el modo narrativo y el modo lógico científico. Para estos autores el modo lógico científico, representa a la persona como pasivo/a frente a fuerzas internas y externas que moldean sus vidas (Impulsos, impactos, transferencias, etc.). En cambio, el modo narrativo sitúa a la persona como protagonista de su propio mundo o historia. Es un mundo interpretativo en donde recontar una historia es contar una historia nueva, generando nuevos significados a medida que la persona con sus semejantes, van reescribiendo y moldeando sus vidas y relaciones (Epston y White, 1993, White 2015 y 2016). Muy resumidamente, exponemos algunos principios fundamentales de la Terapia Narrativa (Epston y White, 1993): El problema es el problema (ética de la externalización de los problemas), las historias moldean nuestras vidas, existen historias dominantes/problemáticas que saturan nuestras vidas, pero también, existen historias subyugadas/alternativas (trama y contratrama).

La posición del terapeuta es descentrada pero influyente, posición de no experto-profesional. Descentrado, en el sentido de no situarse solamente desde las teorías para interpretar a las personas de una forma unívoca, e influyente, en el sentido de que la persona recobre la sensación de agencia personal, ese sería el Telos de la terapia narrativa. Se basa también, en una ética de la colaboración, no del control, en relación con los consultantes. La imposibilidad de conocer o tener acceso a una realidad "objetiva", ya que, todo conocimiento requiere un acto de interpretación. Y la interpretación tiene que ver con quien interpreta, que, a su vez, se relaciona con los aprendizajes particulares de "ese" interpretante (basándose en los planteamientos de Gregory Bateson).

La propuesta de White precisamente, se basa en la generación de una serie de mapas ${ }^{14}$ de trabajo, en los cuales busca rescatar los aspectos preferidos de la persona, sus intereses, sueños, valores y esperanzas. Para ello, se debe generar un "territorio" seguro de identidad, con conversaciones terapéuticas que contribuyan a recobrar el sentido de agencia personal (el control de la propia vida), con temáticas que enaltezcan a las

13. La terapia narrativa inicialmente es conocida como un enfoque, luego se posiciona como terapia y posteriormente es denominada como práctica narrativa (White, 2007).

14. La noción de mapas debe ser entendida en dos aspectos a lo menos. El primero de ellos es, la analogía propuesta por la antropóloga Barbara Myerhoff de que: "el mapa no es el territorio" y, segundo, mapa entendido como una posibilidad de abordaje y de abrir conversaciones, no debe ser entendido un mapa cualquiera de narrativa, por ejemplo, el mapa de reautoría, como la técnica de re-autoría. Además, el mapa contempla y entremezcla aspectos ontológicos, epistemológicos, teóricos, metodológicos, procedimentales, teleológicos y éticos. White y Epston, han sido enfáticos en trazar la distinción fundamental entre mapa y técnica, en la cual, la técnica en sí misma, emerge como una acción sin mayor mediación reflexiva o interpretativa, por su parte el mapa, es una posibilidad abierta, más que un manual o pasos a seguir sin excepción. 
las personas con las se trabaja, con descubrir los actos de resistencia que ellas o ellos han generado frente al abuso, ya que generalmente, lo que funda un acto de resistencia, está relacionado con algo que para la persona es importante, un valor, un sueño, una esperanza, etc. Importante es mencionar que, los valores de los que aquí se habla, no son los valores que culturalmente son aceptados como los válidos o universales. La terapia narrativa alienta a la generación de significados propios, frente a los significados que poseen las disciplinas profesionales, ya que estos no son los que interesan en narrativa. Muy por el contrario, interesa el valor subjetivo de la experiencia y la polisemia de los significados o, en otras palabras, el modo subjuntivo de la cultura.

Cuando se sostienen conversaciones terapéuticas que intenten evidenciar los propósitos abrazados para la propia vida, como lo proponen White y Epston, los valores y creencias preciados para las personas, las aspiraciones, esperanzas y sueños, las formas de vivir preferidas por las personas y como ello se plasma en los actos de lo cotidiano, se está contribuyendo a la generación de agencia personal.

En este sentido, los autores proponen como práctica, la generación de mapas narrativos, a través de la cual se pretende abordar de forma respetuosa y en base a una relación ética-política-horizontal, la cual, perfectamente puede ser la base de un tipo de investigación social. A este respecto, algunos de los mapas narrativos desarrollados por White son: Mapa de Reautoría, Mapa de Remembranza, Mapa de lo ausente pero implícito, Externalización (mapa de declaración de posición 1), Conversaciones de excepción (mapa de declaración de posición 2) y el mapa que nos convoca en el presente artículo: Ceremonias de definición y testigos externos.

\section{Conocimiento Global y conocimiento local: La Ceremonia}

Para la terapia narrativa, el poder-conocimiento tiene un lugar central, respecto del lugar y rol de las teorías que se utilizan para entender la conducta humana -Ciencias Sociales y Filosofía principalmente-, pero también, en las relaciones que se establecen con los otros. El conocimiento no sería una abstracción neutral, por el contrario, este posee un componente político, en el sentido de las relaciones de poder que existen entre el conocimiento científico u "objetivo" y el conocimiento local o subyugado (Epston y White, 1993; White, 2015).

Las ceremonias de definición y testigos externos, son una forma particular de entrevista y poseen la característica de relevar los conocimientos locales, situados y singulares de personas. Sus luchas y sobrevivencias, en general, enaltecer la vida de las personas. Otra de las características de las entrevistas ceremoniales, es que, logran horizontalizar las relaciones e incluir a los otros en los procesos terapéuticos "individuales". En este caso, ejemplificaremos esto, con la vivencia de Clarita ${ }^{15}$ y su familia.

En breve: Clarita experimentó una situación de ASI de parte del esposo de una tía por línea materna, cuando ella devela, otra tía por la misma línea, a la cual llamaremos Claudia, devela igualmente. El proceso terapéutico de Clarita comenzó identificando los territorios seguros, los aspectos no colonizados por el abuso, sus preferencias, sueños y valores (elemento central en Narrativa), posterior a ello, se indagan sobre los principales efectos que tuvo en su vida y sus relaciones la experiencia de ASI, para de esta manera, externalizar dichos efectos y lograr que Clarita identifique sus luchas y resistencias frente a la experiencia abusiva. De igual forma, tuvimos conversaciones de re-autoría individual y familiar, para lograr afianzar esos aprendizajes, historiarlos e identificarlos en el panorama de identidad (valores, sueños, esperanzas, modo subjuntivo de la cultura) y panorama de acción (acciones concretas

15. Los nombres que se utilizan acá, son de carácter ficticio, pero la situación obedece a una ceremonia de definición que tuvo lugar con una familia (madre, padre, hija y tía por línea materna). 
que las personas hacen y no siempre son capaces de ver, ya que, el problema o en este caso, la sintomatología totaliza la experiencia de la persona). En el ámbito familiar, se trabajó con líneas de tiempo narrativas, identidad preferida y el camino de la vida ${ }^{16}$, todo ello, tendiente a fortalecer las historias subyugadas, los conocimientos locales-familiares (madre, padre y Clarita).

Todo este escenario posibilitó la emergencia de un territorio seguro y una contratrama robusta, para hacer frente al abuso de forma familiar, integrando a Claudia (tía por línea materna, víctima de ASI de parte de la misma figura). Ello fue una decisión conversada tanto con Clarita, los padres y Claudia, en sesiones individuales y posteriormente familiares. La ceremonia tuvo lugar en una tetería en calle Serrano, en el Barrio Puerto de Valparaíso ${ }^{17}$. Es importante mencionar que, en Narrativa los espacios terapéuticos son múltiples, no solo el espacio "seguro", privilegiado y artificial del box es el lugar para estos encuentros. En este caso, doblemente importante el espacio, en tanto, era un lugar que la familia frecuenta, se encuentra y comparte momentos íntimos.

La ceremonia de definición y testigos externos tuvo la siguiente estructura: Claudia como protagonista de la entrevista, indagando sobre los efectos del ASI y sus estrategias de afrontamiento y sobrevivencia. Clarita como testigo y segunda en ser entrevistada en base a lo que escuchó de Claudia. Los padres de Clarita como testigos de ambas conversaciones, sin participación y una colega a la cual llamaremos Ximena, como testigo de ambas conversaciones y a quien también se le formularon preguntas.

La ceremonia comienza consultando a Claudia, sobre sus motivaciones para contribuir en el proceso de Clarita y por qué era importante. Esas primeras consultas están enfocadas en sondear y elevar los aspectos valóricos de las personas, lo que protegen o cuidan, así como también, la importancia de las relaciones familiares -en este caso-.

Posterior a ello, se sondean los efectos que tuvo el ASI en Claudia, tanto a nivel individual, relacional, familiar y social, ello con el objeto de externalizar los efectos que, en este caso eran "el temor a los hombres" y a las experiencias de interacción social. En palabras de Claudia: "los hombres eran unas bestias y unos monstruos". Ideas totalizadas respecto del otro, esta era la trama dominante en la vida de Claudia posterior al ASI. Los recursos desplegados por Claudia, dicen relación con explorar racionalmente esas ideas totalizadas y ver posibilidades de resolver sus propias limitaciones, ello con ejercicios de autocalma. Eso contribuyó a disminuir las sensaciones de temor generalizadas que poseía respecto de las figuras masculinas. Las reflexiones posteriores de Claudia hacen alusión a que no se debe generalizar ni tener temor a todo el mundo, porque existen figuras masculinas que no son maltratantes o abusivas, allí se logra apreciar claramente como la contratrama (figuras no abusivas), comienza a debilitar la trama dominante del problema (figuras masculinas abusivas).

Claudia logra identificar, que el apoyo de otras personas fue fundamental en su debilitamiento del problema, lo que es esencial en las ceremonias de definición. Aunque en un comienzo, las respuestas de las personas que escucharon la experiencia de ASI en Claudia, tendieron a minimizar los hechos y a no dar importancia, ello es consecuente con lo que plantea White (2016), sobre las respuestas que comúnmente damos frente a los sentires del otro, son denigrantes, que tienden al menosprecio e incluso ofensivas. Posterior a ello, encontró otros tipos de respuestas, que fueron alentadoras y sanadoras para ella. Y, finalmente lo develó y comentó a su familia, quienes fueron responsivos y dieron credibilidad a lo que informaba Claudia. En esta parte de la entrevista se intenciona que, en los procesos individuales es muy beneficioso incluir a otras personas que hayan pasado por experiencias similares, en tanto, esa relación que las une, es distinta a la relación que une a la persona con su terapeuta, por ejemplo.

16. Por razones de espacio y del eje central del presente artículo, no se comentarán cada uno de estos abordajes.

17. La terapia narrativa posee elementos que se distancian enormemente con otros abordajes terapéuticos, sobre todo, los de corte más clásico. Ya que, en Narrativa creemos que, cualquier espacio es potencialmente terapéutico, sabiendo guiar las conversaciones, incluso una tetería en el Barrio Puerto de Valparaíso, se configuró como un lugar donde tuvo surgimiento un proceso terapéutico. 
En otro momento familiar, cuando Clarita devela, es Claudia quien apoya y alienta a que comente esta situación frente a la familia. Una testigo externa -Claudia-, mediante sus respuestas de apoyo y resonancia posibilitan una develación protegida. Igudfimente, importante es, que la develación de Clarita facilita la develación de Claudia, allí encontramos otra experiencia en común, que brinda espacios de trabajo terapéutico en las ceremonias de definición.

Claudia identifica dos palabras que describen lo que ella fue haciendo para lidiar con los efectos del ASI: enfrentar y confrontar. Enfrentar los efectos que estaba teniendo en ella el ASI y confrontar a la persona que la trasgredió, esos dos elementos están sustentados en un lema familiar que es, "seguir adelante", ello es consecuente con otro planteamiento en Narrativa: las personas siempre responden y no son pasivas frente a las experiencias (White, 2015, 2016). Finaliza esas reflexiones mencionando "esto no va a determinar mi vida", esa frase de Claudia, es una síntesis perfecta para lo que se conoce como, vidas multihistoriadas (Epston y White, 1993; White, 2015, White, 2016). Las cuales contribuyen a minimizar los efectos totalizantes del abuso.

En ese momento de la entrevista, finalizan las consultas hacia Claudia, para centrarnos en Clarita. Este es uno de las principales y potentes estrategias de las ceremonias de definición, entrevistar al otro, a la testigo -en este caso Clarita, respecto de la entrevista que se sostuvo con Claudia-. Y esta segunda parte, está caracterizada por la indagación de cuatro categorías específicas: la primera, sobre las expresiones o palabras, también de los que es importante para la vida de esa persona (Claudia). La segunda, imágenes que hayan llamado la atención, metáforas expresadas, sensaciones, propósitos, valores creencias, etc. La tercera y cuarta categoría de indagación, se relaciona con la persona que ocupó el rol de testigo y sus sentires -en este caso Clarita-. Y, se relacionan con las resonancias experimentadas o sea, lo que se sintió al escuchar a Claudia y finalmente la Katarsis ${ }^{18}$ o movimiento emocional.

Entonces se consulta a Clarita, respecto de la primera categoría de indagación (Expresiones o Palabras): "¿De todo lo que ha dicho Claudia, qué cosas llamaron tu atención, expresiones, palabras o significados que hayan llamado tu atención?" ante lo cual, responde: "me llamó la atención eso de no marcar la vida" (refiriéndose a que, la experiencia de ASI en Claudia, fue algo que no determinó su vida por completo). "Y eso de que hay que seguir adelante". Clarita, al profundizar sobre el porqué es importante para Claudia, "el no determinar la vida", ello está relacionado profundamente con el lema familiar de seguir adelante y también de vivir sus propios procesos, en el caso de Claudia el confrontar y en enfrentar.

Luego de ello, exploramos la segunda categoría de indagación (Imágenes y Metáforas): “¿Cuáles fueron las imágenes que vienen a ti, que te ha llamado la atención, ¿qué te imaginaste al escuchar a Claudia?”. La imagen que relata Clarita, es la cara de ambas al momento de hablar del abuso, luego de las sensaciones de soledad que imponen estas experiencias, luego Clarita sentencia, "vi lo que yo viví y sentí, más que lo que Claudia". Esta frase nos habla de las resonancias que se producen en las ceremonias de definición y testigos externos, al escuchar a otro hablar sobre las vivencias de ASI, se genera la sensación de no estar solo en ello y de cercanía emocional con las propias vivencias y sensaciones. En definitiva, una experiencia en común que abre caminos de conversación potencialmente terapéuticos.

Al pasar a la tercera categoría (Resonancias): “¿Qué cosas de las que ha dicho Claudia, se conectan con tus vivencias, tus emociones, contigo?", casi inmediatamente después de la pregunta, Clarita responde: "Sentí eso de no saber qué hacer, no tener claras las cosas, de no poder hablar". Esto estaba acompañado con la pregunta constante de: ¿Qué va a pasar ahora?, referente al hablar, al hacer la denuncia, al proceso judicial, al proceso de terapia. Esta pregunta aparece en Clarita durante todo el proceso de develación, denuncia, declaraciones en Fiscalía, frente a ello, se le consulta sobre el presente: “¿Qué pasa con esa pregunta ahora?", frente a ello, Clarita responde: "que me vaya bien en el colegio", de forma tal, que sus

18. Katarsis rescatando la etimología griega, no es la catarsis del desahogo emocional que comúnmente escuchamos o leemos, la katarsis se relaciona más bien, con el movimiento y transporte emocional. 
sus prioridades, posterior al proceso terapéutico han cambiado sustancialmente y la preocupación se centra en un aspecto de la vida cotidiana, como lo es, los estudios de enseñanza media que cursaba Clarita. Y finaliza con el lema familiar: ¡Seguir adelante!

Posteriormente, se le consulta sobre la cuarta categoría (Movimiento o Katarsis): “¿Si te preguntara para dónde te movió esta conversación? ¿Cambió tu forma de sentir en este momento?" esas preguntas resuenan de una forma distinta en Clarita, ya que responde: "no habíamos vuelto a hablar más de esto". Haciendo alusión al abuso, siendo la segunda vez en la vida de Claudia y Clarita el hablar del abuso con Claudia, en ese momento, el terapeuta se entera de esta situación y frente a ello, integra una nueva pregunta: "¿Y cómo es para ti eso? ¿Volver a hablar del abuso ahora?", ante ello responde con seguridad: "Es como aliviador" y se sentía bien. Se formula una última pregunta: “¿Qué sensación te queda sobre esto que hemos escuchado y hablado?", ante lo cual responde: "Estoy tranquila porque la Claudita está bien". Lo que nos vuelve a ilustrar que, las resonancias emocionales entre Clarita y Claudia están íntimamente relacionadas y el alivio de una, contribuye al alivio de otra.

Finalmente, a Ximena (Trabajadora Social), se le consultan las mismas cuatro categorías y frente a la primera, Ximena responde que le llamó poderosamente la atención sobre el vínculo entre Claudia y Clarita y como ello ha facilitado el proceso de ambas. Sobre la imagen o metáfora consultada, Ximena responde mencionando una escena de la película El Señor de los Anillos, en la cual, hay una escena en que varios combatientes se enfrentan a un dragón y un personaje se quita el casco y era una mujer la que estaba combatiendo, una mujer en medio de un ejército de hombres y luchando con un dragón. Esa escena la relaciona con las formas que Claudia y Clarita tuvieron que lidiar con los efectos del ASI y como han pasado por un proceso de transformación, en la cual, ahora son: "mujeres guerreras", en palabras de Ximena. Esta respuesta se enmarca en uno de los propósitos generales de las ceremonias de definición, que es enaltecer la vida de las personas, honrando sus respuestas y sus luchas (White, 2016).

Frente a la tercera categoría de indagación (resonancias), Ximena responde mencionando momentos de su vida, en el que ella se ha sentido vulnerable y tener sensaciones desagradables, reforzando esa respuesta menciona que, todos pasamos por momentos difíciles, independiente si somos terapeutas o no. Esto contribuye enormemente a generar lazos horizontales entre los profesionales y las personas con las cuales se trabaja, no es que, el terapeuta les comenté sus experiencias de dolor en profundidad, sino, al mencionar que también se tienen momentos de dolor y sufrimiento, contribuye a despejar esa sensación que mencionaba Clarita, de soledad frente el abuso. También refuerza el lema familiar de "salir adelante" y como Ximena ha tenido que tomar esa decisión en su propia vida.

La pregunta sobre la Katarsis a Ximena la lleva a responder con elementos de su pasado, en los cuales tuvo que luchar "como una guerrera". Menciona que fue una reconciliación con esa imagen del pasado, donde tuvo que sostener sus propias luchas, al igual que Clarita y Claudia.

Finalizamos la ceremonia de definición consultando a Claudia y Clarita, sobre la imagen de guerreras que impresionó en Ximena. Esa indagación tuvo por objeto el potenciar la sensación de agencia personal (Epston y White, 1993), de control, de poder decidir en sus propias vidas, de recuperar lo colonizado por el abuso. Sus preferencias, su identidad preferida, sus territorios queridos y amados, sus lemas familiares, sus vínculos, como mencionó Clarita: "elegir el camino". 


\section{Conclusiones, discusiones y resonancias}

Las ceremonias de definición, tienen por objeto incluir a otros y otras al proceso de intervención terapéutica. A otros que son testigos externos a la experiencia de ASI en este caso. "Estas ceremonias son rituales que reconocen y "enaltecen" las vidas de las personas, contrariamente a muchos rituales de la cultura contemporánea que las enjuician y las degradan" (White, 2016, p. 196). Al respecto, es común que las personas que han sido víctima de ASI se les responsabilice, bajo una serie de prejuicios sociales validados en ciertos contextos, sobre su participación y responsabilidad en el abuso. De esta forma, responsabilizar a las mujeres, niñas y jóvenes por cómo se visten, que son ellas las que provocan el abuso y por ello han sido víctimas de él. Ello, sin mencionar el trato que, a veces, tienen los operativos sociales encargados de contener, investigar e intervenir en este sentido, los cuales, suelen contribuir a revictimizar a las personas.

Las ceremonias de definición son una forma particular de generar entrevistas, en las cuales se incluyen a otras personas. Quienes deben ser preparados cuidadosamente, ya que lo que se busca es, rescatar todas las luchas, actos de resistencia, valores, sueños y esperanzas, en este caso de la población infantojuvenil que ha sido víctima de ASI. Por lo tanto, la inclusión de testigos externos ${ }^{19}$ debe estar en consonancia con los principios éticos de la terapia narrativa y para estos efectos, de la investigación social también. La particularidad de los testigos, cuando se trabajan temáticas relacionadas al abuso, es que esos y esas testigos pueden ser otros jóvenes que han experimentado abuso. Pero como se debe tener especial cuidado en la inclusión de los testigos, es sumamente beneficioso, incluir a la población infantojuvenil que ya lleva un proceso avanzado de terapia, lo cual implica que deben tener cierto nivel de estabilización afectiva y familiar, ya que si esto se descuida, su interacción pudiera ser no del todo beneficiosa para la relación dada entre los participantes de la ceremonia (identidad grupal, identidad personal transformada a partir de la relación con otro legítimamente válido), como también incluir a quienes han pasado por otras instancias sociojudiciales, como el Tribunal de Familia, Fiscalía o el proceso de peritaje.

Cuando se incluye a otros jóvenes al proceso terapéutico, se genera un contexto colaborativo, de respeto mutuo y de confianza lúcida, con claridad en los límites y conversaciones que allí tendrán cabida. Las resonancias que se generan, son un catalizador del aumento de la agencia personal, en tanto, al conversar con otros que han tenido la misma experiencia y que han pasado por distintos dispositivos sociojudiciales, contribuyen a horizontalizar la experiencia y vivencia. Ya que, se significará de forma muy distinta lo que el joven comente a otro joven que haya sido víctima de ASI, sobre el proceso de juicio oral, por ejemplo. Que este juicio sea comentado por un terapeuta cualquiera, ya que, el terapeuta que ha de ir a juicio, asistirá en calidad de testigo no de víctima de ASI. Y el joven que asesora a otro joven, lo hará en calidad de víctima y su vivencia le será mucho más significativa a ese otro joven que, aún no asiste a juicio oral. En este sentido "las narrativas personales son coautoría en el contexto de las relaciones que les son significativas" (White, 2016, p. 208).

El mapa de ceremonia de definición, plantea cuatro categorías de indagación que se efectúan en la entrevista junto a los testigos. La primera de ellas es la expresión: Identificar y hablar de lo que más le atrajo de lo que escuchó (las expresiones que le hicieron sentir lo que esta persona valora en su vida): Qué de ese relato es especial y distinto. La segunda, se refiere a la imagen: Imágenes evocadas (metáforas, imágenes mentales acerca de su identidad o sus relaciones). Reflexionaremos sobre lo que esas imágenes pueden reflejar lo que para la persona entrevistada es importante en la vida. La tercera es sobre la resonancia: Lo que resonó en su interior. "Interés encarnado". Cómo se conecta con su historia. Y la última, es la Katarsis o el transporte: Hacia dónde lo transportó (en sus pensamientos, reflexiones, entendimientos de la vida, posibilidades de actuar), que no hubiese llegado de otra forma. Este ejercicio de indagar en las categorías, se efectúa en

19. No existe un número recomendado de testigos, aunque generalmente varía de 3 a 4 testigos. Hay experiencias documentadas de testigos con mayor amplitud numérica, tal es el caso de un "juicio social" llevado a cabo en Nueva Zelanda desde los pueblos originarios de West Pappu a la sociedad civil, en la cual participaron más de 400 testigos-público (Denborough, 2012). 
primera instancia, con los testigos, luego de entrevistar al actor principal -por llamarlo de alguna manera-, luego de ello, de los testigos han respondido a las cuatro categorías de indagación, se puede regresar al actor principal e indagar con él o ella, sobre las mismas categorías, de forma tal, que se generen nuevas resonancias y en general nuevos conocimientos situados. Lo que es sumamente consecuente con el proceso recursivo que mencionábamos al comienzo del presente artículo, sobre la relación dialéctica entre intervención e investigación social.

En otro sentido, la ceremonia de definición se posiciona como un antídoto contra el aislamiento, ya que, "ayuda a las personas a ser vistas en sus propios términos, gracias a la presencia de personas que atestiguan su valor" (White, 2016, p. 212). Todo esto, va engrosando la contra-trama del dolor y potencia la agencia personal, bajo una fuerte ética de colaboración y respeto, principios que le son comunes a la intervención e investigación social.

Sobre la ética de la colaboración -principio fundamental en terapia narrativa-, ella puede tener tres vertientes comprensivas. La primera es, que son las personas y sus vivencias las que las hacen expertas en sus propias vidas, en contra al saber profesional/técnico de quienes trabajan (colaboran), con ellas (profesionales). La segunda se relaciona con la relación de respeto colaborativo, no desde el control social o institucional ${ }^{20} \mathrm{y}$ la tercera que importa aquí, es que, los niños, niñas y jóvenes se convierten en asesores de otros niños, niñas y jóvenes que han vivido experiencias de trauma y abuso sexual infantil. Asesorando al asesor es "Cuando se trata a los pacientes como asesores de sí mismos, de otros pacientes y del terapeuta, ellos se sienten con mayor autoridad sobre sus propias vidas, sobre sus problemas y sobre la solución a tales problemas" (Epston y White, 2004, p. 208). Acá vuelve a emerger el tema de la agencia personal, ya que es otro, un par, quien está asesorando a otro par. No es un terapeuta cualquiera (figura de poder), quien tiene la "solución" al problema de quien lo sufre. En este sentido, se hace mención a las poderosas resonancias que generan las sesiones en las cuales, se incluyen a otros niños, niñas y jóvenes, generalmente con el proceso de terapia más avanzado o cuando ya han desarrollado un territorio seguro desde donde hablar. Cuando se realizan ceremonias de definición, los testigos externos, que en este caso son otros niños que han vivenciado trauma y ASI, se generan efectos de resonancia en los cuales se comparten los aprendizajes desarrollados, las formas de afrontamiento y cómo fueron lidiando con los efectos de las experiencias transgresoras, por ejemplo.

Finalmente, la posibilidad de contemplar la intervención social (terapéutica), como forma de investigación social, en este caso particular a través de la ceremonia de definición y testigos externos, abre un campo de discusión, en tanto, lo que emerge en dicha ceremonia no son solo relatos desprovistos de significados. Como también, relatos sin conocimiento y como se mencionó anteriormente, el conocimiento subyugado es el que le interesa a la Narrativa, no el conocimiento global, universal ni menos, el conocimiento "objetivo".

Al mencionar que, son los conocimientos locales los que nos interesan, dejaremos entre paréntesis las teorías que manejamos, en este caso, sobre abuso sexual infantil, trauma, develación, procesos judiciales, etc. Ya que, como vimos, esas sensaciones y experiencias fueron relatadas de forma muy distinta de la teoría, fueron relatadas desde la experiencia, desde el cuerpo, desde el interés encarnado y desde las resonancias. Y más importante aún, esos conocimientos locales fueron sumamente significativos tanto para Clarita, Claudia y Ximena. Este conocimiento proviene de la experiencia misma, es un tipo de conocimiento deconstructivo, emerge en la relación con el otro y posibilita la emergencia de la agencia personal.

Este proceso de generación de conocimiento local, le es muy útil a las personas que han vivido experiencias similares, posibilita trazar distinciones sobre su experiencia y la de los demás. De igual forma, la ceremonia de definición realizada a Clarita, Claudia y Ximena, ha quedado registrada en audio y ahora en papel. El audio -con las autorizaciones correspondientes-, puede ser utilizado en los procesos de otros NNJ sobrevivientes de ASI y, el registro en el papel, puede generar actos de conocimiento local, en las personas que tengan acceso a leer esta experiencia.

20. Para quienes se desempeñan en organismos colaboradores del Servicio Nacional de Menores, esta colaboración debe ponerse en tensión y suspenderse al momento de, enterarse de nuevas vulneraciones de derecho en los NNJ. O sea, la colaboración finaliza, cuando algún derecho fundamental el transgredido. 


\section{Bibliografía}

1. Ander-Egg, E. (1994). Historia del Trabajo Social. Buenos Aires: Lumen.

2. Aylwin, N. \& Solar, O. (2002). Trabajo Social Familiar. Santiago de Chile: Ediciones universidad católica de Chile.

3. Bertrado, P. \& Toffaneti, D. (2004). Historia de la Terapia Familiar los personales y las ideas, Barcelona: Paidós Ibérica S.A.

4. Bustos, A. \& Vidal, C. (2014). Consecuencias neurobiológicas y psicosociales del abuso sexual infantil: necesidad de un abordaje multi y transdisciplinario. En Tapias, A. (Coordinadora), Victimología en América Latina; un enfoque psicojurídico. Colombia: Editorial ALPJF.

5. Bustos, A. (2014). Modelos contemporáneos de intervención en Trabajo Social: revisión bibliográfica del modelo narrativo. Revista Perspectivas de la UCSH, $N^{\circ}$ $25,2014 \cdot$ ISSN $0717-1714 \cdot 67-83$

6. Carballeda, A. (2004). La Intervención en lo Social. Buenos Aires: Paidós

7. Corbeta, P. (2007). Metodología y técnicas de investigación social. Madrid: McGRAW-HILL/INTERAMERICANA DE ESPAÑA.

8. De Robertis, C \& Pascal, H. (2006). La Intervención Colectiva en Trabajo Social, la acción con grupos y comunidades. Buenos Aires, Argentina: Hvmanitas.

9. De Robertis, C. (1994). Metodología de la Intervención en Trabajo Social. Buenos Aires, Argentina: Hvmanitas.

10. Durrant, M. \& White, Ch. (2006.) Terapia del Abuso Sexual, Barcelona: Gedisa.

11. Echeburúa, E. \& Guerricaechevarría, C. (2000). Abuso sexual en la infancia: víctimas y agresores, Un enfoque clínico. Barcelona: Ariel.

12.Epston, D. (1994). Obras escogidas. Barcelona: Gedisa.

13.Epston, D. \& White, M. (1993). Medios Narrativos para fines terapéuticos, Barcelona: Paidós.

14. Escartín, M. (1998). Manual de Trabajo Social. Alicante: AGUACLARA.

15. Finkelhor, D. \& Browne, A. (1985). The traumatic impact of child abuse: A conceptualization. American Journal of Orthopsychiatry, 55(4), 530-541.

16. Hernández, R., Fernandez, C., \& Baptista, P. (2014). Metodología de la investigación. México D.F.,: McGRAW-HILL/INTERAMERICANA DE ESPAÑA.

17. Murillo, J. (2012). Confianza lúcida, Santiago: Uqbar.

18. Matus, T. (1999). Propuestas Contemporáneas en Trabajo Social, Hacia una Intervención Polifónica. Buenos Aires: Editorial Espacio.

19. Malacrea, M. (2011). Trauma y reparación. El tratamiento del abuso sexual en la infancia. Madrid: Paidós.

20. Minuchin, S. (1974). Familias y Terapia Familiar. Barcelona: Gedisa.

21. Morgan, A. (2000). What Is Narrative Therapy? Adelaida: Dulwich Centre Publications.

22. OMS, Departamento de Salud Reproductiva e Investigación, Escuela de Higiene y Medicina Tropical de Londres, Consejo Sudafricano de Investigaciones Médicas (2013). Estimaciones mundiales y regionales de la violencia contra la mujer: prevalencia y efectos de la violencia conyugal y de la violencia sexual no conyugal en la salud, p. 2. Para obtener información individual por paises, véase The World's Women 2015, Trends and Statistics, capitulo 6, Violence against Women, Departamento de Asuntos Económicos y Sociales de las Naciones Unidas, 2015 y Base de datos mundial sobre la violencia contra las mujeres de ONU Mujeres.

23. Perrone, R. \& Nannini, M. (1996). Violencia y abusos sexuales en la familia. Un abordaje sistémico y comunicacional. Buenos Aires: Paidós.

24. Quintero, A. (2004). Trabajo Social y Procesos Familiares, Buenos Aires: Lumen/Humanitas.

25. Stupiggia, M. (2010). El Cuerpo Violado. Aproximación Psicocorporal al Trauma del Abuso. Santiago: Cuatro Vientos.

26. UNICEF (2014). Ocultos a plena luz: Un análisis estadístico de la violencia contra los niños, p. 167.

27. Van der Kolk, B. (2015). El cuerpo lleva la cuenta. Cerebro, mente y cuerpo en la superación del trauma. Barcelona: Elefhteria.

28. Van der Hart, O., Nijenhuis, E. \& Stelee, $\boldsymbol{K}$ (2005). Dissociation: An insufficiently recognized major feature of complex posttraumatic stress disorder. Journal of Traumatic Strees, 18, 412-423. New York, Estados Unidos.

29. White, M. (2007). Maps of Narrative Practice, New York: Editorial Norton

30. White, M. (2004). Guías para una Terapia Familiar Sistémica, Barcelona: Gedisa.

31. White, M. (2002). El Enfoque Narrativo en la Experiencia de los Terapeutas, Barcelona: Gedisa.

32. White, M (2015). Póstumo, Práctica Narrativa la conversación continua, Santiago: PRANAS Chile ediciones.

33. White, M. (2016). Mapas de la Práctica Narrativa, Santiago: PRANAS Chile ediciones. 